\title{
Effects of isosorbide mononitrate loaded nanoparticles conjugated with anti-Staphylococcus aureus $\alpha$-toxin on Staphylococcus aureus biofilms
}

\author{
YAQIAN ZHANG ${ }^{1,2}$, YULIN ZHAO ${ }^{1,2}$, DONG DONG ${ }^{1,2}$, XIAOPING LI $^{3}$, \\ ZHI LI ${ }^{4}$, SIYU LI $^{1,2}$ and JUAN WANG ${ }^{3}$ \\ ${ }^{1}$ Department of Rhinology, ${ }^{2}$ Institute of Clinical Medicine and ${ }^{3}$ Department of Traditional Chinese Medicine, \\ The First Affiliated Hospital of Zhengzhou University; ${ }^{4}$ School of Pharmaceutical Science, \\ Zhengzhou University, Zhengzhou, Henan 450052, P.R. China
}

Received September 20, 2019; Accepted November 19, 2019

DOI: 10.3892/etm.2019.8344

\begin{abstract}
Staphylococcus aureus (S. aureus) is associated with recalcitrant chronic infection, especially in chronic rhinosinusitis (CRS). S. aureus infection and biofilms cause poorer postsurgical outcomes. We developed isosorbide mononitrate (ISMN) loaded nanoparticles conjugated with an anti-Staphylococcus aureus alpha-toxin (anti-S. aureus $\alpha$-toxin) antibody that could target biofilms and investigated their anti-biofilm effect. Anti-S. aureus $\alpha$-toxin antibody coupled immunoliposomes were generated. The effect of ISMN immunoliposomes on $S$. aureus biofilm formation and their anti-biofilm efficacy were examined using the crystal violet method and confocal laser scanning microscopy, respectively. Relative biofilm viability at $24 \mathrm{~h}$ was tested using the alamarBlue assay. The biofilm formation inhibitory effect on all concentrations of ISMN immunoliposomes was stronger than that of ISMN liposomes and free ISMN $(\mathrm{P}<0.05)$. At concentrations of 45 and $23 \mathrm{mg} / \mathrm{ml}$, the inhibitory effect of ISMN liposomes was stronger than that of free ISMN $(\mathrm{P}<0.05)$, while at $11 \mathrm{mg} / \mathrm{ml}$, the inhibitory effect of ISMN liposomes was the same as that of ISMN (P>0.05). At 45 and $23 \mathrm{mg} / \mathrm{ml}$, the inhibitory effect of ISMN immunoliposomes on formed biofilms was greater than that of ISMN liposomes and free ISMN $(\mathrm{P}<0.05)$ and the inhibitory effect of ISMN liposomes was stronger than that of free ISMN $(\mathrm{P}<0.05)$. At $11 \mathrm{mg} / \mathrm{ml}$, ISMN immunoliposomes, ISMN liposomes, and ISMN had the same effect on formed biofilms $(\mathrm{P}>0.05)$. In conclusion, ISMN immunoliposomes nearly completely destroy biofilm structure. ISMN immunoliposomes provide a promising approach for treating infectious
\end{abstract}

Correspondence to: Dr Yulin Zhao, Department of Rhinology, The First Affiliated Hospital of Zhengzhou University, 1 Eastern Jianshe Road, Zhengzhou, Henan 450052, P.R. China

E-mail: zhaoyulin27@163.com; uqw2tn@163.com

Key words: chronic rhinosinusitis, Staphylococcus aureus, biofilm, ISMN immunoliposomes, nanoparticles diseases caused by $S$. aureus biofilms, including refractory CRS, chronic skin infection, sepsis, and osteomyelitis.

\section{Introduction}

Chronic rhinosinusitis (CRS) is a common rhinology disease; the reported prevalence of Staphylococcus aureus (S. aureus) in CRS patients is $61 \%$ (1). Bacterial biofilms are considered as a common and important cause of persistent infections; biofilms require up to $1,000 \mathrm{x}$ higher antibiotic doses for effective treatment compared to planktonic cells, thus hindering eradication (2,3). Long-term use of antibiotics and emerging resistant bacteria pose a great threat to human health. Thus, a new drug delivery system needs to be developed to overcome the antibiotic resistance and to eliminate biofilm.

Healthy individuals present high concentrations of nitric oxide (NO) in the sinuses (4), NO plays a role in antimicrobial and antiviral effects, keeping the sinuses relatively sterile, while enhancing the clearance function of mucosa cilia $(5,6)$. CRS patients have significantly lower levels of sinonasal NO (7). Some studies have demonstrated that high NO concentrations suppress $S$. aureus biofilm growth $(8,9)$. Isosorbide mononitrate (ISMN), widely used as a NO-donor in the trials, has been shown to be safe for various applications $(10,11)$. Different types of liposomes, which can reduce drug toxicity, have also been certified for clinical use (12). A new type of liposome, immunoliposomes (antibody-conjugated liposomes), have attracted increasing attention owing to their potential use as targeted drug delivery systems (13). Currently, immunoliposomes are extensively used for treating cancer cells. Targeted delivery of drugs encapsulated in nanoparticles can increase drug accumulation at the tumor site and slow down drug elimination in blood circulation (14).

The $S$. aureus $\alpha$-hemolysin (HLA) is an important virulence factor, which can also promote bacterial biofilm formation. The potential role of anti-HLA antibodies in targeting molecules for the functionalization of anti-biofilm drug-loaded nanovectors has not been studied to date. Thus, we combined the anti-HLA antibodies with ISMN liposomes to treat infectious diseases caused by S. aureus biofilms. The anti-Staphylococcus aureus 
alpha-toxin (anti-S. aureus $\alpha$-toxin) monoclonal antibody can neutralize $S$. aureus exotoxins, as well as target the nanoparticles to the biofilm.

\section{Materials and methods}

Liposome preparation. ISMN liposomes were prepared using the film dispersion method. Egg lecithin and cholesterol were mixed at a weight ratio of 3:1 and then dissolved in $5 \mathrm{ml}$ chloroform. The chloroform was slowly removed under reduced pressure using a rotary evaporator to deposit a thin film of dry lipid on the inner wall of the flask. The dry lipid film was hydrated with $10 \mathrm{ml}$ phosphate-buffered saline (PBS) solution containing $45 \mathrm{mg} / \mathrm{ml}$ ISMN for $30 \mathrm{~min}$ to obtain the liposomes. The resultant mixture was then successively filtered through $0.45 \mu \mathrm{m}$ membranes. The prepared liposomes were stored at $4^{\circ} \mathrm{C}$ until used.

The study was approved by the Ethics Committee of the First Affiliated Hospital of Zhengzhou University (Zhengzhou, China).

Construction of the pET28a-Hla recombinant plasmid and expression of the HLA protein. HLA genes were PCR amplified using $S$. aureus (ATCC25923) genomic DNA as the template with the following conditions: at $95.0^{\circ} \mathrm{C}$ for $5 \mathrm{~min} ; 30$ cycles at $95.0^{\circ} \mathrm{C}$ for $30 \mathrm{sec}$, at $58.0^{\circ} \mathrm{C}$ for $30 \mathrm{sec}$, and at $72.0^{\circ} \mathrm{C}$ for $1 \mathrm{~min}$; and $72.0^{\circ} \mathrm{C}$ for $5 \mathrm{~min}$. The HLA PCR product was cloned into linearized pET28a using the Fast-Fusion Cloning Kit (GeneCopoeia, Inc.), resulting in recombinant plasmid pET28a-Hla, which was verified by PCR and restriction enzyme analysis. pET28a-Hla was transformed into Escherichia coli BL21 (DE3) sensory cells and HLA protein expression was induced with $0.4 \mathrm{mM}$ Isopropyl $\beta$-D-thiogalactoside at $20^{\circ} \mathrm{C}$. The bacterial cells were resuspended in buffer $(20 \mathrm{mM}$ Tris- $\mathrm{HCl}, 0.5 \mathrm{M} \mathrm{NaCl}$, and $20 \mathrm{mM}$ imidazole, $\mathrm{pH}$ 8.0) and the HLA recombinant protein was obtained by $\mathrm{Ni}^{2+}$-affinity chromatography.

Preparation of monoclonal antibody. The purified HLA recombinant protein was used as an antigen to immunize BALB/c mice. Freund's complete adjuvant (Sigma-Aldrich; Merck KGaA) was used to emulsify the antigen. A suspension of spleen cells from the immunized mice was fused with myeloma SP $2 / 0$ cells to screen for hybridoma cells that could stably secrete the antibody. The hybridoma cell was inoculated into the abdomen of mice and the hydroperitoneum was collected and purified using the octanoic acid-ammonium sulfate method to obtain the monoclonal antibody against HLA. Western blot analysis was used to determine its specificity.

Preparation of ISMN immunoliposomes. Twenty-five microliters of $25 \%$ glutaraldehyde were added to $1 \mathrm{ml}$ ISMN liposomes and the mixture was maintained at $25^{\circ} \mathrm{C}$ for $10 \mathrm{~min}$. The excess glutaraldehyde was removed by saline dialysis for $3 \mathrm{~h}$. Subsequently, the anti-S. aureus $\alpha$-toxin monoclonal antibody was conjugated with liposomes that reacted with glutaraldehyde (overnight at $4^{\circ} \mathrm{C}$ with shaking). Immunoliposomes were stored at $4^{\circ} \mathrm{C}$ until used.

Encapsulation percentage determination. ISMN immunoliposomes were centrifuged at 2,035 x g for $20 \mathrm{~min}$ at $4^{\circ} \mathrm{C}$ using an ultrafiltration tube (EMD Millipore). The ultrafiltrate was diluted with PBS and then analyzed by ultraviolet spectrophotometry $(210 \mathrm{~nm})$ to determine the amount of free $\operatorname{ISMN}\left(\mathrm{m}_{\text {free drug }}\right)$, the $\mathrm{m}_{\text {total drug }}$ was $450 \mathrm{mg}$. An ISMN standard curve was generated using ISMN solutions of known concentrations. Encapsulation efficiency (En $\%)=\mathrm{m}_{\text {total drug }}-\mathrm{m}_{\text {free drug }} / \mathrm{m}_{\text {total drug }}$.

Coupling rate determination. Immunoliposomes were centrifuged at $11,300 \mathrm{x} \mathrm{g}$ for $30 \mathrm{~min}$ at $4^{\circ} \mathrm{C}$ and the supernatant (free protein) was carefully removed to another tube. The immunoliposomes were resuspended in an equal volume of PBS. The concentration of free protein was determined using the BCA kit (Solarbio). Coupling rate $=1-\mathrm{m}_{\text {free protein }} / \mathrm{m}_{\text {total protein }}$.

Suspension preparation. Biofilm forming strain S. aureus ATCC25923 was used in this study. Bacterial cultures were established as previously described (3). Briefly, bacterial strains (frozen glycerol stock) were inoculated onto nutrient agar (Oxoid) plates and incubated overnight at $37^{\circ} \mathrm{C}$ for recovery. A bacterial suspension of $1 \mathrm{McFarland}$ unit in $0.9 \%$ saline prepared using single colonies from the plate was used for subsequent experiments.

Effect of immunoliposomes on biofilm formation. The immunoliposomes were resuspended in tryptose phosphate broth (TPB) (Sigma-Aldrich; Merck KGaA) and ISMN was dissolved in TPB at a concentration of $45 \mathrm{mg} / \mathrm{ml}$. The bacterial suspension was diluted, $15 \mu \mathrm{l}$ of bacterial suspension was mixed with $135 \mu \mathrm{l}$ of the different drug dosage forms (immunoliposomes, liposomes, and ISMN), transferred into 96-well microplates (Corning Life Sciences Plastic), and incubated for $48 \mathrm{~h}$ at $37^{\circ} \mathrm{C}$ under $5 \% \mathrm{CO}_{2}$ and $90 \%$ humidity.

The 96-well microplate was rinsed twice in saline to remove planktonic bacteria and then dried for $10 \mathrm{~min}$ at $25^{\circ} \mathrm{C}$. Next, $200 \mu \mathrm{l}$ of methyl alcohol (Hengxing, Tianjin, China) was added to each well and incubated at $25^{\circ} \mathrm{C}$ for $15 \mathrm{~min}$. Then, $200 \mu \mathrm{l} /$ well of the crystal violet was added and incubated statically at $25^{\circ} \mathrm{C}$ for $15 \mathrm{~min}$, distilled water was applied to remove the extra dye following decanting, and $250 \mu \mathrm{l} /$ well of $95 \%$ ethyl alcohol was added and incubated at $25^{\circ} \mathrm{C}$ for $1 \mathrm{~h}$. Finally, the absorbance of the samples was measured using a microplate reader at $560 \mathrm{~nm}$.

Effect of immunoliposomes on formed biofilms. For biofilm growth, the $S$. aureus suspension was diluted 1:10 in TPB and $150 \mu 1$ of the dilution was pipetted into the wells of 96-well clear-bottom microplates (Corning Life Sciences Plastic, NY, USA) and incubated at $37^{\circ} \mathrm{C}$ under $5 \% \mathrm{CO}_{2}$ and $90 \%$ humidity for $48 \mathrm{~h}(3,15)$.

The prepared biofilm-coated 96-well microplate was rinsed twice with saline to remove planktonic bacteria and $200 \mu \mathrm{l}$ of ISMN immunoliposomes, ISMN liposomes and ISMN, respectively, were added to the wells for $24 \mathrm{~h}$ at $37^{\circ} \mathrm{C}$, followed by another two washes. The alamarBlue assay (Invitrogen; Thermo Fisher Scientific, Inc.) was performed to test the viability of the challenged biofilm according to the manufacturer's instructions; $250 \mu \mathrm{l} /$ well of the alamarBlue (1:10 dilution in TPB) was added and incubated statically at $37^{\circ} \mathrm{C}$ for $1 \mathrm{~h}$. Finally, the fluorescence intensity of the samples was measured with a FLUOstar OPTIMA plate reader (excitation, $530 \mathrm{~nm}$; 
Table I. Relative absorbance following different interventions in S. aureus biofilm formation.

\begin{tabular}{lccr}
\hline Groups & $45 \mathrm{mg} / \mathrm{ml}$ & $23 \mathrm{mg} / \mathrm{ml}$ & $11 \mathrm{mg} / \mathrm{ml}$ \\
\hline Control & $100 \%$ & $100 \%$ & $100 \%$ \\
ISMN & $35.70 \pm 2.87 \%$ & $76.37 \pm 5.65 \%$ & $82.61 \pm 5.68 \%$ \\
ISMN-Lipo & $18.26 \pm 5.21 \%$ & $60.31 \pm 3.83 \%$ & $82.50 \pm 3.10 \%$ \\
[ISMN-Lipo]-AntiHLA & $2.16 \pm 0.22 \%$ & $38.42 \pm 4.44 \%$ & $62.38 \pm 5.01 \%$ \\
\hline
\end{tabular}

S. aureus, Staphylococcus aureus.

emission, $590 \mathrm{~nm}$; BMG Labtech). PBS was used as the negative control and wells that did not contain biofilms were stained as the background. All treatments were carried out in triplicate and the experiments were repeated twice.

To observe the biofilms following different intervention formulations, $300 \mu \mathrm{l}$ of the bacterial suspension was added to CLSM, 8-well culture slides (BD Biosciences) and incubated at $37^{\circ} \mathrm{C}$ for $24 \mathrm{~h}$ to form the $S$. aureus biofilm. Next, the medium was carefully replaced with fresh TPB and the slide was incubated at $37^{\circ} \mathrm{C}$ under $5 \% \mathrm{CO}_{2}$ and at $90 \%$ humidity for another $48 \mathrm{~h}$ to allow further biofilm formation. Once the biofilm formed, different drug dosages and concentrations were added to the wells.

The slide was rinsed twice with $0.9 \% \mathrm{NaCl}$ to remove planktonic bacteria $(15,16)$ and $300 \mu \mathrm{l} /$ well of immunoliposomes, liposomes, and ISMN at different concentrations was added for $24 \mathrm{~h}$. PBS was applied as the non-treatment control. Following intervention, the samples were fixed with $300 \mu \mathrm{l} /$ well of $5 \%$ glutaraldehyde (Zhiyuan) for $30 \mathrm{~min}$ prior to staining. Next, $300 \mu 1 /$ well of the SYTO9+PI (Invitrogen; Thermo Fisher Scientific, Inc.) mixture in saline was added to each well and incubated in the dark for $15 \mathrm{~min}$ at room temperature. All steps were followed by two saline washes. After removing the upper chamber of the culture slide, the samples were sealed with glycerol (Dingguo) and examined using a Nikon (Nikon Microsystems) confocal laser scanning microscopy with 60x objective and $0.25 \mu \mathrm{m}$ for laser scanning step size; PI, excitation $561 \mathrm{~nm}$ and emission $610 \mathrm{~nm}$; SYTO9, excitation $476 \mathrm{~nm}$ and emission $510 \mathrm{~nm}$. For each sample, the full thickness of the biofilm was scanned along the z-stacks and the experiments were repeated three times. Image processing and analysis were performed using Nikon NIS-Elements (Nikon) and ImageJ 1.43 (Wayne Rasband, National Institutes of Health).

Statistical analysis. Parametric data are expressed as mean \pm standard deviation. Depending on the type of data, significant differences between multiple groups were confirmed by the Kruskal-Wallis test or one-way analysis of variance (ANOVA); pairwise comparisons were conducted using the Bonferroni method. Difference were considered statistically significant at $\mathrm{P}<0.05$.

\section{Results}

Amplification of target gene. The HLA gene was PCR amplified using $S$. aureus genomic DNA. The obtained amplified fragment was of the expected size, $960 \mathrm{bp}$.
Preparation of HLA monoclonal antibody. The pET28a-Hla recombinant plasmid was successfully transfected into cells and the resulting purified HLA recombinant protein was used as an antigen to immunize BALB/c mice. Hybridoma cells secreting anti-HLA monoclonal antibodies were obtained and the antibodies were successfully prepared.

Immunoliposome characterization. ISMN immunoliposomes formed a milky white suspension on gross examination. ISMN liposomes remained stable without changing their appearance, hydrodynamic diameter and encapsulation percentage $(\mathrm{P}<0.05)$ for one month at $4^{\circ} \mathrm{C}$.

The physicochemical properties of the samples, namely hydrodynamic diameter and $\zeta$-potential, were obtained using dynamic light scattering. The average hydrodynamic diameter of the ISMN immunoliposomes was $175.7 \mathrm{~nm}(\mathrm{PDI}=0.235)$ and the $\zeta$ potential was $-1.18 \mathrm{mV}$. We found that the produced liposomes were negatively charged particles, regardless of whether they contained the drug.

The ISMN immunoliposome encapsulation percentage was $17.6 \%$, much higher than previously published (3). The coupling rate of the anti-S. aureus $\alpha$-toxin monoclonal antibody to ISMN immunoliposomes was $32.86 \%$.

Effect of immunoliposomes on biofilm formation. The effects of different drug dosage forms (immunoliposomes, liposomes, and free ISMN) with ISMN concentrations of 45, 23 and $11 \mathrm{mg} / \mathrm{ml}$ were examined. ISMN immunoliposomes intervention reduced biofilm formation to $2.16 \pm 0.22,38.42 \pm 4.44$ and $62.38 \pm 5.01 \%$, respectively; ISMN liposomes intervention reduced biofilm formation to $18.26 \pm 5.21,58.31 \pm 3.15$ and $82.50 \pm 3.10 \%$, respectively; and ISMN intervention reduced biofilm formation to $35.7 \pm 2.87,76.37 \pm 5.65$ and $82.61 \pm 5.68 \%$, respectively. At these drug concentrations, the inhibitory effect of ISMN immunoliposomes on biofilm formation was greater than that of ISMN liposomes and ISMN $(\mathrm{P}<0.05)$. At drug concentrations of 45 and $23 \mathrm{mg} / \mathrm{ml}$, the inhibitory effect of ISMN liposomes on biofilm formation was stronger than ISMN $(\mathrm{P}<0.05)$, while at $11 \mathrm{mg} / \mathrm{ml}$, the inhibitory effect of ISMN liposomes on biofilm formation was the same as ISMN (P>0.05; Table I and Fig. 1).

The effect of immunoliposomes on formed biofilms. The inhibition ratio was calculated following normalization to the mean fluorescent intensity of the control wells (biofilms without any intervention) to compare the differences between the different interventions. 
Table II. Inhibition rate after following different interventions in S. aureus biofilms.

\begin{tabular}{lcrr}
\hline Groups & $45 \mathrm{mg} / \mathrm{ml}$ & $23 \mathrm{mg} / \mathrm{ml}$ & $11 \mathrm{mg} / \mathrm{ml}$ \\
\hline ISMN & $62.67 \pm 4.04 \%$ & $21.33 \pm 1.53 \%$ & $16.33 \pm 2.08 \%$ \\
ISMN-Lipo & $77.33 \pm 3.06 \%$ & $36.67 \pm 3.51 \%$ & $19.00 \pm 5.29 \%$ \\
[ISMN-Lipo]-AntiHLA & $96.67 \pm 2.08 \%$ & $50.33 \pm 5.86 \%$ & $21.33 \pm 3.06 \%$ \\
\hline
\end{tabular}

S. aureus, Staphylococcus aureus.

Table III. Mean green fluorescence intensity following different interventions in S.aureus biofilms.

\begin{tabular}{lrrr}
\hline Groups & \multicolumn{1}{c}{$45 \mathrm{mg} / \mathrm{ml}$} & $23 \mathrm{mg} / \mathrm{ml}$ & $11 \mathrm{mg} / \mathrm{ml}$ \\
\hline Control & $1,285.00 \pm 60.91$ & $1,285.00 \pm 60.91$ & $1,285.00 \pm 60.91$ \\
ISMN & $843.90 \pm 76.01$ & $1,038.00 \pm 47.54$ & $1,077.00 \pm 52.41$ \\
ISMN-Lipo & $739.60 \pm 49.18$ & $918.6 \pm 57.97$ & $1,075.00 \pm 41.33$ \\
[ISMN-Lipo]-AntiHLA & $616.30 \pm 70.14$ & $848.20 \pm 41.07$ & $1,062.00 \pm 49.66$ \\
\hline
\end{tabular}

S. aureus, Staphylococcus aureus.

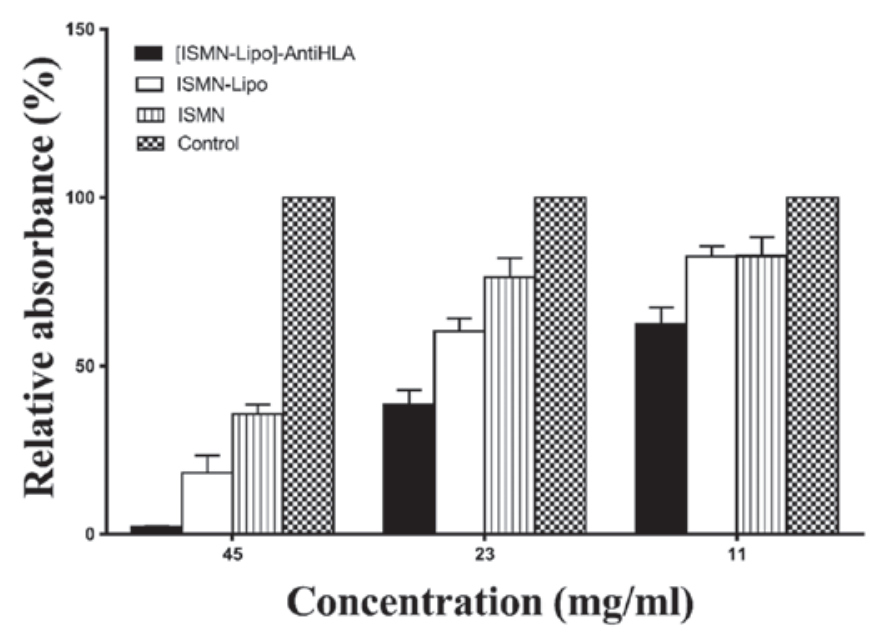

Figure 1. Effect of ISMN immunoliposomes, ISMN liposomes, and ISMN intervention on biofilm formation. The crystal violet assay was used to evaluate the effect of immunoliposomes, liposomes, and ISMN on biofilm formation. The $\mathrm{x}$-axis represents the different concentrations and the $\mathrm{y}$-axis represents the relative absorbance. ISMN, isosorbide mononitrate.

The inhibition rate with ISMN concentrations of 45,23 and $11 \mathrm{mg} / \mathrm{ml}$ was $96.67 \pm 2.08,50.33 \pm 5.86$ and $21.33 \pm 3.06 \%$, respectively, for ISMN immunoliposomes; $77.33 \pm 3.06,36.67 \pm 3.51$ and $19.00 \pm 5.29 \%$, respectively, for ISMN liposomes; and 62.67 $\pm 4.04,21.33 \pm 1.53$ and $16.33 \pm 2.08 \%$, respectively, for ISMN. At drug concentrations of 45 and $23 \mathrm{mg} / \mathrm{ml}$, the inhibitory effect of ISMN immunoliposomes on formed biofilms was stronger than ISMN liposomes and ISMN $(\mathrm{P}<0.05)$ and the inhibitory effect of ISMN liposomes was stronger than ISMN $(\mathrm{P}<0.05)$. At $11 \mathrm{mg} / \mathrm{ml}$, ISMN immunoliposomes, ISMN liposomes, and ISMN had the same effect on formed biofilms $(\mathrm{P}>0.05$; Table II and Fig. 2).

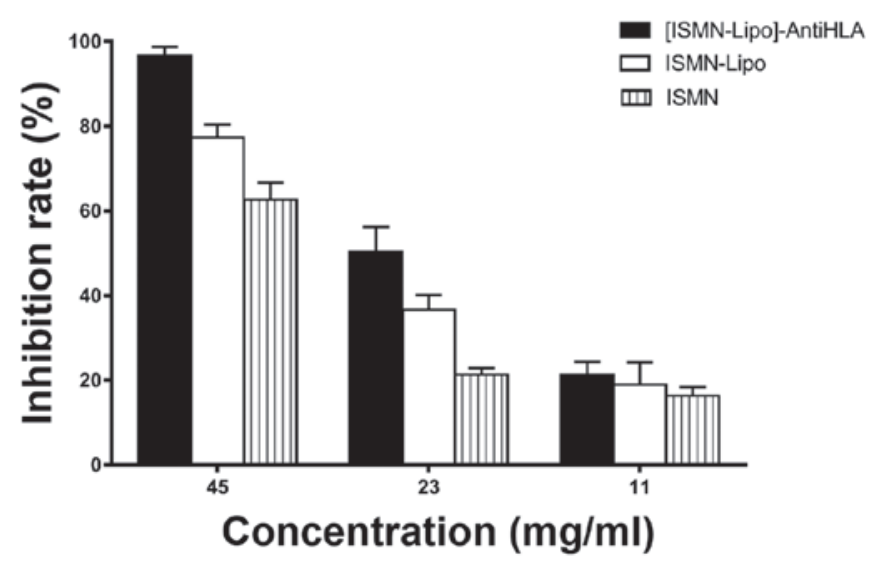

Figure 2. Effect of ISMN immunoliposomes, ISMN liposomes, ISMN on formed $S$. aureus biofilms. The alamarBlue assay was used to evaluate the effect of immunoliposomes, liposomes, and ISMN on formed biofilms. The $\mathrm{x}$-axis represents the different concentrations and the y-axis represents the inhibition rate. ISMN, isosorbide mononitrate; S. aureus, Staphylococcus aureus.

Confocal laser scanning microscopy (CLSM) analysis. The killing effect of immunoliposomes, liposomes, and free ISMN on biofilms was verified using CLSM with fluorescence quantitative analysis. In this experiment, SYTO9 and PI interacted with the nucleic acids of live and dead bacteria, which were visualized as green and red, respectively. The S. aureus biofilm in the control group appeared as a large cloud, in which the dead and live bacteria and polysaccharide matrix were clustered together. At a drug concentration of $45 \mathrm{mg} / \mathrm{ml}$, the immunoliposomes almost completely eradicated the biofilm; only a handful of scattered bacteria remained (Fig. 3). At concentrations of 45 and $23 \mathrm{mg} / \mathrm{ml}$, the green fluorescence intensity of all intervention groups was lower than that of the control group and the difference was statistically significant 


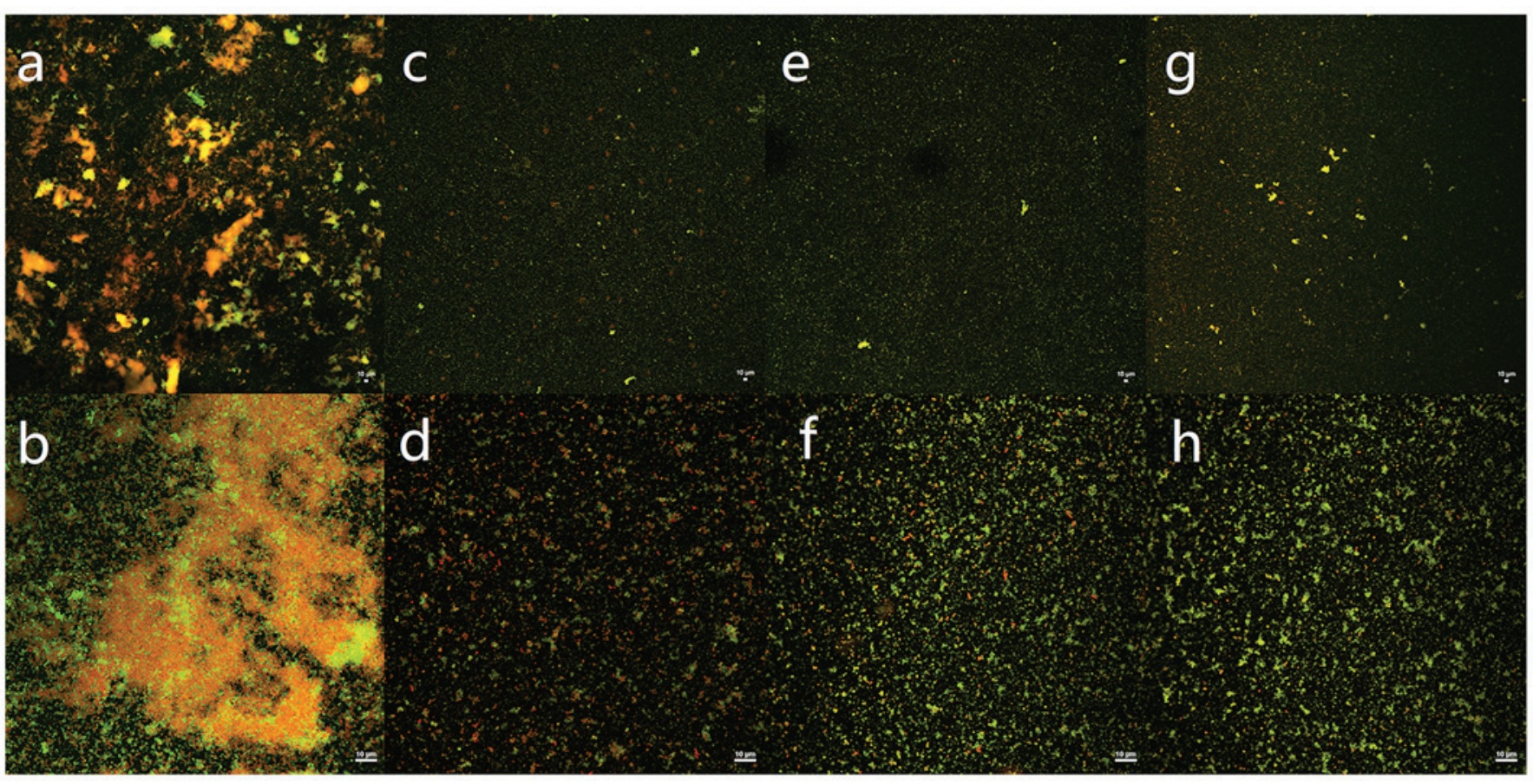

Figure 3. Confocal laser scanning microscopy (CLSM) images displaying the S. aureus biofilm. SYTO9 and PI interacted with the nucleic acids of live bacteria and dead bacteria, which are shown as green and red, respectively. (a, c, e and g) The biofilm was observed under 10x objective; (b, d, f and h) The biofilm was observed under 60x objective. (a and b) The biofilm was treated with PBS. (c and d) The biofilm was treated with $45 \mathrm{mg} / \mathrm{ml}$ immunoliposomes. (e and f) The biofilm was treated with $45 \mathrm{mg} / \mathrm{ml}$ liposomes. (g and h) The biofilm was treated with $45 \mathrm{mg} / \mathrm{ml}$ ISMN. S. aureus, Staphylococcus aureus; ISMN, isosorbide mononitrate.

between any two groups $(\mathrm{P}<0.05)$. At $11 \mathrm{mg} / \mathrm{ml}$, the green fluorescence intensity of all intervention groups was lower than that of the control group and the difference was statistically significant $(\mathrm{P}<0.05)$; however, there was no statistically significant difference between any two dosage forms $(\mathrm{P}>0.05$; Table III and Fig. 4). Moreover, quantitative analysis of green fluorescence intensity obtained from CLSM was consistent with the alamarBlue assay results.

\section{Discussion}

In this study, immunoliposomes were successfully produced and the average hydrodynamic diameter of the ISMN immunoliposomes was $175.7 \mathrm{~nm}(\mathrm{PdI}=0.235)$. The encapsulation percentage of ISMN immunoliposomes was $17.6 \%$, which was much higher than previously reported; the diameter was also smaller than previously reported (3). Previous studies have shown that the smaller the particle size of liposomes, the better the liposomes are able to permeate biofilms (15). Encapsulation efficiency plays a vital role in drug delivery to the biofilm. We used an orthogonal test to determine the optimum dosage of egg lecithin and cholesterol; the liposomes we obtained had a smaller diameter and higher encapsulation efficiency.

The preliminary study confirms that $45 \mathrm{mg} / \mathrm{ml} \mathrm{ISMN}$ can be used to eradicate bacterial biofilms. Furthermore, we investigated the effect of different concentrations of immunoliposomes, liposomes, and free ISMN on formed biofilms and biofilm formation. Our results show that immunoliposomes with $45 \mathrm{mg} / \mathrm{ml} \mathrm{ISMN} \mathrm{had} \mathrm{the} \mathrm{greatest} \mathrm{anti-biofilm} \mathrm{effects}$ (including formed biofilms and biofilm formation) compared with the same concentration of free ISMN and ISMN liposomes. Further mechanism of how the immunoliposomes affect the delivery of the NO donor to the biofilm is needed.

At a concentration of $11 \mathrm{mg} / \mathrm{ml}$, immunoliposomes had a significantly stronger anti-biofilm effect (biofilm formation) than the corresponding concentration of liposomes and free drug and the difference was statistically significant $(\mathrm{P}<0.05)$. The biofilm formation process is divided into several stages, namely adhesion, colony formation, maturation, and aging. The effect of ISMN immunoliposomes on biofilms began at the adhesion stage or during colony formation. Thus, $11 \mathrm{mg} / \mathrm{ml}$ ISMN immunoliposomes may intervene more effectively with biofilm formation than the same concentration of ISMN liposomes and free ISMN; the higher local drug concentration could effectively inhibit and interfere with biofilm formation.

In addition, $11 \mathrm{mg} / \mathrm{ml}$ ISMN immunoliposomes had a stronger anti-biofilm effect (formed biofilm) than the corresponding concentration of liposomes and free drug; however, the difference was not statistically significant $(\mathrm{P}>0.05)$. The reason for this may be that the biofilm was aging or mature; although the immunoliposomes targeted the drug to the biofilm, the drug concentration might have been too low to effectively eliminate a mature stage biofilm. Thus, once the biofilm was formed, it was difficult to eradicate, especially at low drug concentrations. Therefore, the advantages of immunoliposomes were less obvious compared with ISMN liposomes and free ISMN. In contrast, at early stages of biofilm formation low drug concentrations were able to effect biofilm formation during the $48 \mathrm{~h}$ interaction period.

There are several reasons explaining the increased antibiotic resistance of biofilms compared with free bacteria: 
a
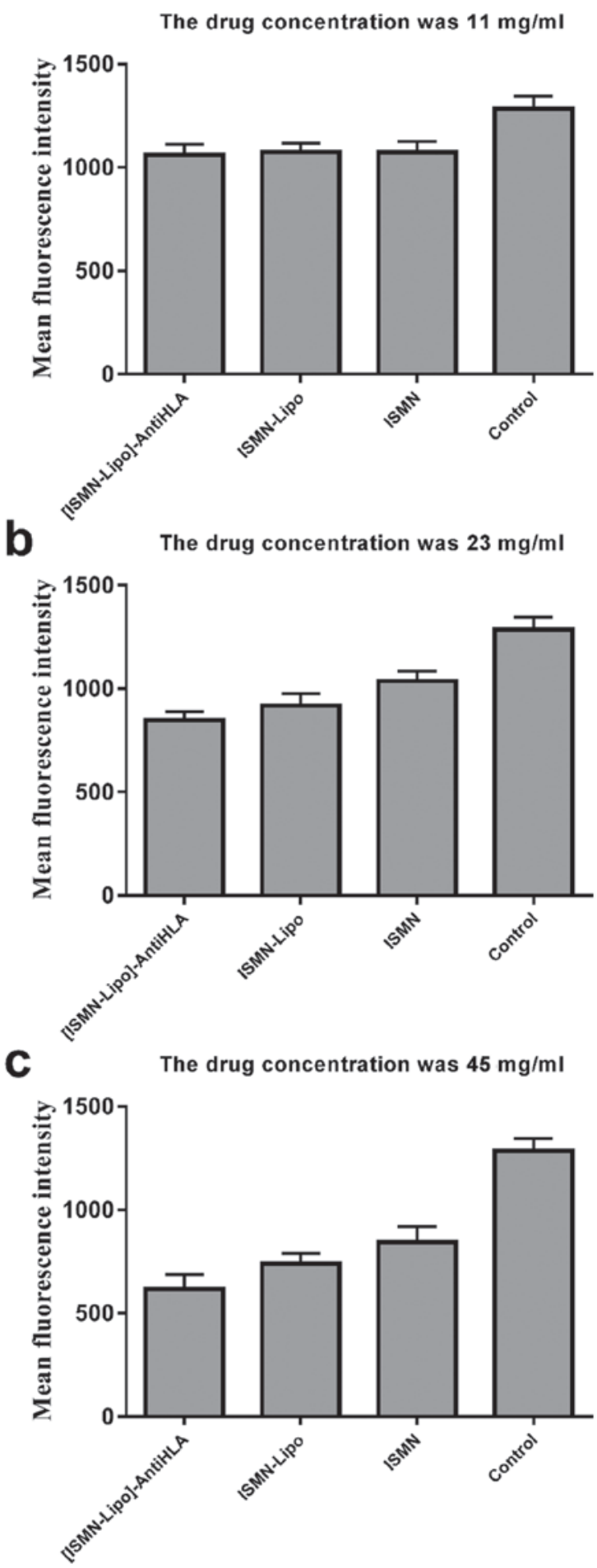

Figure 4. Mean green fluorescence intensity following intervention with different concentrations of ISMN immunoliposomes, ISMN liposomes, and ISMN. SYTO9 and PI interacted with live (green) and dead bacteria (red), respectively. The $\mathrm{x}$-axis represents the different interventions and the $\mathrm{y}$-axis represents the mean green fluorescence intensity. (a) Drug concentration, $11 \mathrm{mg} / \mathrm{ml}$; (b) drug concentration, $23 \mathrm{mg} / \mathrm{ml}$; and (c) drug concentration $45 \mathrm{mg} / \mathrm{ml}$. ISMN, isosorbide mononitrate.

i) The extracellular matrix secreted by bacteria in the biofilm can form a physiological and metabolic barrier (17), which can prevent or greatly reduce the entry of antibiotics into cells $(18,19)$. ii) The microenvironment in the biofilm is complex and there may be some regional differences in oxygen concentration, osmotic pressure, and $\mathrm{pH}$, resulting in different susceptibility to antibiotics and other drugs. iii) The specific growth patterns of the biofilm can enable bacteria to escape the host immune system $(20,21)$. iv) Nutritional limitation: the accumulation of metabolites in biofilms and the consumption of oxygen and nutrients causes bacteria in the biofilm to starve and enter a non-vegetative state, resulting in fewer sensitive cells in the biofilm (22-24). v) Bacteria in the biofilm may exhibit specific biological phenotypes, which are controlled by specific genes.

Immunoliposomes have been studied extensively in tumor treatment. Immunoliposomes have significant advantages in clinical use (25). Firstly, in terms of ensuring drug effects, immunoliposomes not only reduce drug dosage, but could also reduce or prevent the adverse effects of drugs in the patient. Secondly, immunoliposomes could be used to establish new medical approaches and improve the efficacy of currently used hydrophilic (low membrane trespassing capacity) macromolecules (26). Thirdly, immunoliposomes can target tumors and easily control drug dosage. Bacterial biofilm possesses a certain spatial structure and the biofilm matrix may protect bacteria against drug permeability; hence, it is difficult for common drugs to permeate and eradicate the biofilm. Thus, we designed ISMN immunoliposomes comprised of ISMN encapsulated within liposomes coupled to an anti-S. aureus $\alpha$-toxin monoclonal antibody. Encapsulating ISMN with liposomes allowed the drug to permeate the biofilm more easily via lipid fusion (27). Furthermore, coupling with the anti-S. aureus $\alpha$-toxin monoclonal antibody ensured that ISMN could selectively act on the biofilm, which would not only improve the efficacy of ISMN against biofilms, but could also reduce drug dosage and decrease adverse drug reactions. The hydrophobic properties of the bacterial cell wall have also been shown to impact liposomes penetration and enhance drug mobility through the biofilm matrix (28). Compared with topical antimicrobials, which have difficulty penetrating the biofilm matrix, immunoliposomes could easily combine with and enter into bacterial biofilm; the retention of immunoliposomes in the biofilm could facilitate drug release in close proximity of the bacteria over extended periods of time (22), which is extremely important for effective biofilm eradication. This study focused on the S. aureus biofilm in vitro, further studies are required to confirm this and to investigate its safety and efficacy in the animal model of CRS.

Immunoliposomes, which provide a potential new form of dosage that is effective and safe, will hopefully be conducive to decreasing antibiotic use and consequently reducing the risk of developing drug resistance. The optimum concentration of immunoliposomes selected here, which demonstrated the best anti-biofilm effects, could provide a starting drug concentration for future animal experiments.

In conclusion, the findings of this study indicate that ISMN immunoliposomes were the most effective formulation for eradicating bacterial biofilms. Furthermore, we highlight the advantages of immunoliposomes as a novel drug delivery system for biofilm eradication. Future in vivo studies are required to determine their safety and efficacy prior to topical clinical application. 


\section{Acknowledgements}

Not applicable.

\section{Funding}

The National Natural Science Foundation of China (Grant Number: 81570901). International cooperation project of science and technology department of Henan province (172102410004); Medical science project of Henan province (SBGJ2018034).

\section{Availability of data and materials}

The datasets used and/or analyzed during the present study are available from the corresponding author on reasonable request.

\section{Authors' contributions}

YaZ, YuZ, DD and XL led the conception and design of this study. YaZ, YuZ, DD, ZL, SL and JW were responsible for the data collection and analysis. YaZ, DD and XL were in charge of interpreting the data and drafting the manuscript. YuZ and SL made revision from critical perspective for important intellectual content. The final version was read and adopted by all the authors.

\section{Ethics approval and consent to participate}

The study was approved by the Ethics Committee of the First Affiliated Hospital of Zhengzhou University (Zhengzhou, China).

\section{Patient consent for publication}

Not applicable.

\section{Competing interests}

The authors declare that they have no competing interests.

\section{References}

1. Boase S, Foreman A, Cleland E, Tan L, Melton-Kreft R, Pant H, Hu FZ, Ehrlich GD and Wormald PJ: The microbiome of chronic rhinosinusitis: Culture, molecular diagnostics and biofilm detection. BMC Infect Dis 13: 210, 2013.

2. Ha KR, Psaltis AJ, Butcher AR, Wormald PJ and Tan LW: In vitro activity of mupirocin on clinical isolates of Staphylococcus aureus and its potential implications in chronic rhinosinusitis. Laryngoscope 118: 535-540, 2008.

3. Jardeleza C, Rao S, Thierry B, Gajjar P, Vreugde S, Prestidge CA and Wormald PJ: Liposome-encapsulated ISMN: A novel nitric oxide-based therapeutic agent against Staphylococcus aureus biofilms. PLoS One 9: e92117, 2014.

4. Abuzeid WM, Girish VM, Fastenberg JH, Draganski AR, Lee AY, Nosanchuk JD and Friedman JM: Nitric oxide-releasing microparticles as a potent antimicrobial therapeutic against chronic rhinosinusitis bacterial isolates. Int Forum Allergy Rhinol 8: 1190-1198, 2018.

5. Barraud N, Hassett DJ, Hwang SH, Rice SA, Kjelleberg S and Webb JS: Involvement of nitric oxide in biofilm dispersal of Pseudomonas aeruginosa. J Bacteriol 188: 7344-7353, 2006.
6. Workman AD, Carey RM, Kohanski MA, Kennedy DW, Palmer JN, Adappa ND and Cohen NA: Relative susceptibility of airway organisms to antimicrobial effects of nitric oxide. Int Forum Allergy Rhinol 7: 770-776, 2017.

7. Hariri BM, McMahon DB, Chen B, Freund JR, Mansfield CJ, Doghramji LJ, Adappa ND, Palmer JN, Kennedy DW, Reed DR, et al: Flavones modulate respiratory epithelial innate immunity: Anti-inflammatory effects and activation of the T2R14 receptor. J Biol Chem 292: 8484-8497, 2017.

8. Kishikawa H, Ebberyd A, Römling U, Brauner A, Lüthje P, Lundberg JO and Weitzberg E: Control of pathogen growth and biofilm formation using a urinary catheter that releases antimicrobial nitrogen oxides. Free Radic Biol Med 65: 1257-1264, 2013.

9. Slomberg DL, Lu Y, Broadnax AD, Hunter RA, Carpenter AW and Schoenfisch MH: Role of size and shape on biofilm eradication for nitric oxide-releasing silica nanoparticles. ACS Appl Mater Interfaces 5: 9322-9329, 2013.

10. Oelze M, Knorr M, Kröller-Schön S, Kossmann S, Gottschlich A, Rümmler R, Schuff A, Daub S, Doppler C, Kleinert H, et al: Chronic therapy with isosorbide-5-mononitrate causes endothelial dysfunction, oxidative stress, and a marked increase in vascular endothelin-1 expression. Eur Heart J 34: 3206-3216, 2013.

11. Müller S, König I, Meyer W and Kojda G: Inhibition of vascular oxidative stress in hypercholesterolemia by eccentric isosorbide mononitrate. J Am Coll Cardiol 44: 624-631, 2004.

12. Yaari Z, da Silva D, Zinger A, Goldman E, Kajal A, Tshuva R, Barak E, Dahan N, HershkovitzD, Goldfeder M, et al: Theranostic barcoded nanoparticles for personalized cancer medicine. Nat Commun 7: 13325, 2016.

13. Anaya-Ruiz M, Bandala C, Landeta G, Martínez-Morales P, Zumaquero-Rios JL, Sarracent-Pérez J and Pérez-Santos M: Nanostructured systems in advanced drug targeting for the cancer treatment: Recent patents. Recent Patents Anticancer Drug Discov 14: 85-94, 2019.

14. Zheng Y, Tang L, Mabardi L, Kumari S and Irvine DJ: Enhancing adoptive cell therapy of cancer through targeted delivery of small-molecule immunomodulators to internalizing or noninternalizing receptors. ACS Nano 11: 3089-3100, 2017.

15. Dong D, Thomas N, Thierry B, Vreugde S, Prestidge CA and Wormald PJ: Distribution and inhibition of liposomes on Staphylococcus aureus and Pseudomonas aeruginosa biofilm. PLoS One 10: e0131806, 2015.

16. Ahmed K, Gribbon PN and Jones MN: The application of confocal microscopy to the study of liposome adsorption onto bacterial biofilms. J Liposome Res 12: 285-300, 2002.

17. Tan Y, Ma S, Leonhard M, Moser D, Haselmann GM, Wang J, Eder D and Schneider-Stickler B: Enhancing antibiofilm activity with functional chitosan nanoparticles targeting biofilm cells and biofilm matrix. Carbohydr Polym 200: 35-42, 2018.

18. Akanda ZZ, Taha M and Abdelbary H: Current review - The rise of bacteriophage as a unique therapeutic platform in treating peri-prosthetic joint infections. J Orthop Res 36: 1051-1060, 2018.

19. Ivanova K, Fernandes MM, Francesko A, Mendoza E, Guezguez J, Burnet $\mathrm{M}$ and Tzanov T: Quorum-quenching and matrix-degrading enzymes in multilayer coatings synergistically prevent bacterial biofilm formation on urinary catheters. ACS Appl Mater Interfaces 7: 27066-27077, 2015.

20. Pires DP, Melo L, Vilas Boas D, Sillankorva S and Azeredo J: Phage therapy as an alternative or complementary strategy to prevent and control biofilm-related infections. Curr Opin Microbiol 39: 48-56, 2017.

21. Figueiredo AMS, Ferreira FA, Beltrame $\mathrm{CO}$ and Côrtes MF: The role of biofilms in persistent infections and factors involved in ica-independent biofilm development and gene regulation in Staphylococcus aureus. Crit Rev Microbiol 43: 602-620, 2017

22. Forier K, Raemdonck K, De Smedt SC, Demeester J, Coenye T and Braeckmans K: Lipid and polymer nanoparticles for drug delivery to bacterial biofilms. J Control Release 190: 607-623, 2014.

23. Martins M, McCusker MP, McCabe EM, O'Leary D, Duffy G and Fanning S: Evidence of metabolic switching and implications for food safety from the phenome(s) of Salmonella enterica serovar Typhimurium DT104 cultured at selected points across the pork production food chain. Appl Environ Microbiol 79: 5437-5449, 2013. 
24. Fauvart M, De Groote VN and Michiels J: Role of persister cells in chronic infections: Clinical relevance and perspectives on anti-persister therapies. J Med Microbiol 60: 699-709, 2011.

25. Yang G and Yin B: Therapeutic effects of long-circulating miR-135a-containing cationic immunoliposomes against gallbladder carcinoma. Sci Rep 7: 5982, 2017.

26. Marques J, Valle-Delgado JJ, Urbán P, Baró E, Prohens R, Mayor A, Cisteró P, Delves M, Sinden RE, Grandfils C, et al: Adaptation of targeted nanocarriers to changing requirements in antimalarial drug delivery. Nanomedicine (Lond) 13: 515-525, 2017.

27. Moles E, Moll K, Ch'ng JH, Parini P, Wahlgren M and Fernàndez-Busquets X: Development of drug-loaded immunoliposomes for the selective targeting and elimination of rosetting Plasmodium falciparum-infected red blood cells. J Control Release 241: 57-67, 2016.
28. Ertem E, Gutt B, Zuber F, Allegri S, Le Ouay B, Mefti S, Formentin K, Stellacci F and Ren Q: Core-shell silver nanoparticles in endodontic disinfection solutions enable long-term antimicrobial effect on oral biofilms. ACS Appl Mater Interfaces 9: 34762-34772, 2017.

This work is licensed under a Creative Commons Attribution-NonCommercial-NoDerivatives 4.0 International (CC BY-NC-ND 4.0) License. 